Centeno, Romina Natalí. Informalidad en el proceso de urbanización de Villa Muñecas (Tucumán, Argentina). GeoGrahos. [En línea]. Alicante: Universidad de Alicante, 10 de enero de 2013, vol. 4, no 34, p. 52-68. [ISSN: 2173-1276].

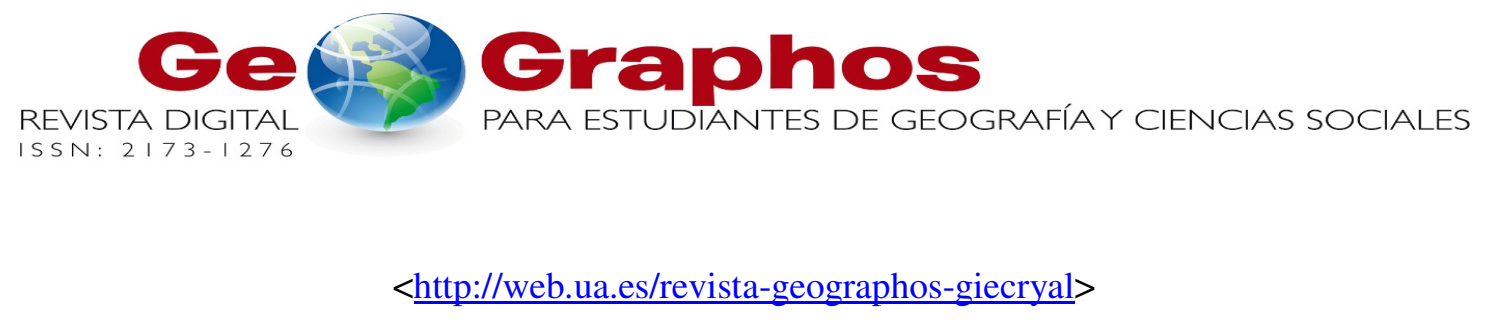

Vol. 4. $\mathrm{N}^{\mathrm{o}} 34$

Año 2013

\title{
INFORMALIDAD EN EL PROCESO DE URBANIZACIÓN DE VILLA MUÑECAS (TUCUMÁN, ARGENTINA)
}

\author{
Romina Natalí Centeno \\ Estudiante de la Licenciatura en Geografía \\ Instituto de Estudios Geográficos “Dr. Guillermo Rohmeder”. Facultad de Filosofía y Letras. \\ Universidad Nacional de Tucumán (San Miguel de Tucumán, Tucumán, Argentina) \\ Correo electrónico: rom_tafi@hotmail.com
}

Recibido: 14 de septiembre de 2012. Devuelto para revisión: 6 de octubre de 2012.

Aceptado: 10 de enero de 2013

\section{RESUMEN}

A lo largo del siglo XX Villa Muñecas, un barrio de clase media-baja periférico de la capital tucumana, ha ido mutando su fisionomía urbana, cantidad de población, provisión de servicios, etc., sin embargo ha conservado una particularidad: la informalidad. Desde el origen del barrio se montaron rancheríos precarios en terrenos fiscales, marginales con pocas actitudes para la urbanización y sin los servicios básicos. Con el transcurso del tiempo, se produjo el loteo legal de un espacio en el que se instaló la población más favorecida socioeconómicamente, sin embargo las crisis económicas que afectaron a la provincia y al país sirvieron de impulsoras de la formación de nuevos asentamientos informales en sectores definidos de Villa Muñecas. En la actualidad se observa una visible sectorización con diversidad de situaciones.

Palabras clave: Proceso de urbanización, Informalidad, Villa Muñecas, Tucumán, Argentina. 


\title{
INFORMALIDAD IN THE PROCESS OF URBANIZATION OF VILLA MUÑECAS (TUCUMÁN, ARGENTINA)
}

\begin{abstract}
Throughout the twentieth century Villa Muñecas, a middle class neighborhood-low peripheral of the capital of Tucumán, has been mutating urban its physiognomy, amount of population, provision of services, etc. , however has retained a special feature: the informality. Since the origin of the neigh boyhoods we remounted rancherios precarious in land tax, marginal with few attitudes for urbanization and without basic services. With the transcurso of the time, produced the loteo legal of a space in which installed the most favoured population socioeconómicamente, however the economic crises that affected to the province and to the country served of impulsoras of the training of new asentamientos informal in sectors defined of Villa Muñecas. In the actuality observes a visible sectorización with diversity of situations.
\end{abstract}

Key words: Process of urbanization, Informalidad, Villa Muñecas, Tucumán, Argentina.

\section{INFORMALIDAD NO PROCESSO DE URBANIZACIÓN DE VILLA MUÑECAS (TUCUMÁN, ARGENTINA)}

\section{RESUMO}

Durante todo o século xx Villa Muñecas, uma classe média periférica baixa do bairro da capital de Tucumán, tem sido mutação urbana a sua fisionomia, quantidade de população, prestação de serviços, etc., porém, manteve uma característica especial: a informalidade. Desde a origen do bairro foram montados rancheríos precária no terreno fiscal, marginal comalg umas atitudes de urbanizacion e sem serviços básicos. Com o transcurso do tempo, produziu-se o loteo legal de um espaço no que se instalou a população mais favorecida socioeconomicamente, no entanto as crises económicas que afectaram à província e ao país serviram de impulsoras da formação de novos assentamentos informais em sectores definidos de Villa Muñecas. Na actualidade observa-se uma visível sectorización com diversidade de situações.

Palabras-chave: Processo de urbanización, Informalidad, Villa Muñecas, Tucumán, Argentina.

\section{INTRODUCCIÓN}

El crecimiento urbano en ciudades medias de América Latina, está marcado por la segregación socio-espacial y la informalidad a causa de la ampliación progresiva de la brecha económica entre grupos sociales; y el Gran San Miguel de Tucumán es un ejemplo de esta situación. 
Como producto del crecimiento urbano, importantes contingentes de población deben asentarse en áreas no aptas para la construcción de viviendas, unido esto al mercado clandestino de viviendas y terrenos al que los individuos de bajos recursos deben acudir para poder acceder a una vivienda propia.

La presente investigación busca analizar el proceso de urbanización de Villa Muñecas desde fines del siglo XIX hasta la actualidad, poniendo énfasis en la relevancia que ha ido adquiriendo la informalidad a lo largo del tiempo. Este caso específico se enmarca en el contexto del crecimiento urbano del aglomerado San Miguel de Tucumán.

El área de estudio se conforma por el sector tradicional de Villa Muñecas, (que se encuentra delimitado por las calles Viamonte al este, Av. Francisco de Aguirre al norte, Delfín Gallo al sur y Castro Barros al oeste), y por Villa Muñecas II o Ampliación Villa Muñecas, según el instituto Provincial de la Vivienda (comprendida entre las calles Castro Barros al oeste, Delfín Gallo al norte Viamonte al este y el Pasaje Monserrat al sur) correspondiente a la fracción censal 2 (radios 01,02,03,04 y 05 de un total de 21 radios en toda la fracción, según el último Censo Nacional), se puede observar su ubicación en el plano aportado por la Dirección de Estadísticas de la Provincia para el año 2003 (véase la figura 1).

\section{Figura 1. Ubicación de Villa Muñecas en el aglomerado tucumano}

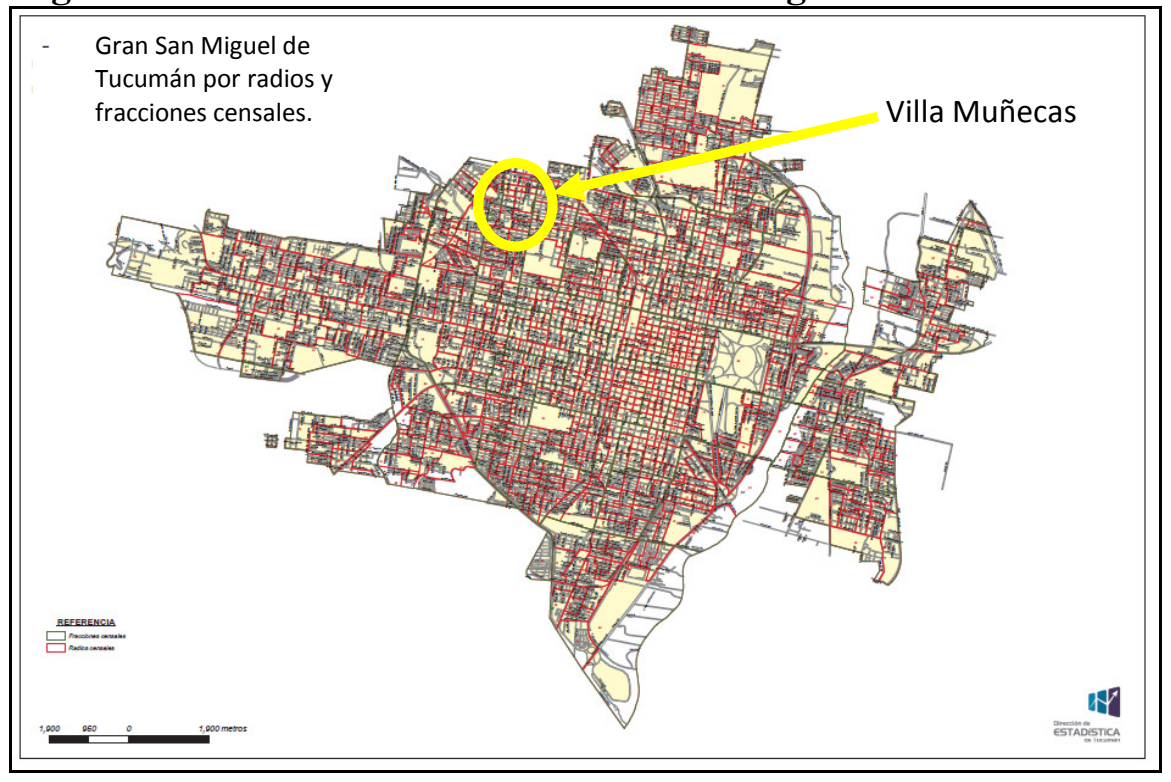

Fuente: Dirección de Estadísticas de la provincia de Tucumán. 2003.

\section{MATERIALES Y MÉTODOS}

En cuanto a lo metodológico: se realizó la recopilación, análisis y fichado de material bibliográfico relativo a la historia de la urbanización de Villa Muñecas en el contexto del crecimiento de San Miguel de Tucumán y su área metropolitana; y material cartográfico. 
Como así también se realizo el trabajo de campo, donde se hicieron entrevistas semiestructuradas a informantes calificados para recabar información acerca del origen y crecimiento inicial de Villa Muñecas a través de testimonios.

Asimismo se procedió a la extracción de datos numéricos de los últimos 50 años, con el fin de estudiar el crecimiento poblacional del área estudiada, de los censos 1960, 1970, 1980, 1991, y 2001 con la proyección correspondiente al año 2010. Destacando la dificultad de comparación entre los mencionados censos, puesto que la división en radios y fracciones censales es diferente para cada caso.

En lo que respecta al crecimiento de la población, a partir de los datos de los censos 19912001 se calculó la tasa de crecimiento intercensal, la cual representa 14,12\%.

\section{ANÁLISIS DE LA INFORMALIDAD}

Como se verá a continuación, el proceso de formación de Villa Muñecas estuvo marcado por la informalidad, más acentuada en ciertos sectores como los márgenes de las vías del tren y las del canal norte.

La informalidad de acceso al suelo urbano, es un fenómeno creciente en el mundo y principalmente en América Latina, es la modalidad predominante del crecimiento de las ciudades.

En general, se considera que el fenómeno de la informalidad urbana es resultante de la pobreza, sin embargo, M. Smolka plantea que "el suelo urbano inasequible no es solo un problema de ingresos bajos, sino también del precio del producto". Por otro lado, según el citado autor "la informalidad no solo es efecto, sino también causa de la pobreza, en la medida en que la población residente en áreas informales es capturada por muchos 'círculos viciosos' que reiteran su condición" (Smolka, 2003, p. 9). Es así como se puede observar en nuestra área de estudio, que familias de bajos recursos en distintas épocas optaron por tomar la vía ilegal $\mathrm{y}$ adquirieren informalmente lotes a través de punteros políticos, u ocupaciones de hecho realizadas en principio por un grupo de personas que se encuentran en igual condición, o bien a través de la compra a otros vecinos que adquirieron su lotes por medio de las modalidades antes mencionadas.

Podríamos decir que hablamos de informalidad cuando las respuestas y acciones, desplegadas en un "espacio diferenciado" por los diversos actores que intervienen en él, se desarrollan en desacuerdo a las normas y reglas consideradas dentro de la lógica formal (Monayar, 2011).

En Villa Muñecas se observa que existe un déficit de viviendas que es producto del rápido incremento poblacional y la baja o nula oferta de viviendas por parte del gobierno o de algún organismo privado, sumado esto a que se trata de una población de bajos recursos que necesita de una mayor flexibilidad de pagos a la hora de comprar su vivienda propia o solicitar un plan de financiamiento. 
En este punto es importante hacer referencia a la globalización y el neoliberalismo, llegado a la Argentina en los '90 que produjo transformaciones productivas y fuertes modificaciones en el mercado de trabajo, causando el desempleo y de la baja de la calidad de vida urbana y rural.

Edesio Fernándes, (miembro de la Teaching Faculty del Lincoln Institute of Land Policy, y de la Development Planning Unit de la Universidad College London) señala que aunque las tasas de crecimiento urbano en América Latina ya no siguen un crecimiento marcado, como hace décadas atrás, la población de esta región se muestra como netamente urbana $(75 \%$ de la población vive en ciudades).

Con respecto a la problemática del crecimiento urbano informal dice que "un número creciente de latinoamericanos sigue adhiriendo a la informalidad: según estimaciones conservadoras, al menos uno de cada cuatro ciudadanos solamente tiene acceso a la tierra urbana y a la vivienda únicamente a través de procesos informales, generando una intensa proliferación de asentamientos informales en áreas urbanas", así la población se asienta en áreas no aptas para la construcción de viviendas, aunado al mercado clandestino de viviendas y terrenos al que la población de bajos recursos debe acudir para poder acceder a una vivienda propia.

Siguiendo a este mismo autor, se pone de manifiesto que "aunque los datos sean siempre imprecisos, en ciudades como Sao Paulo y Río de Janeiro ya se admite oficialmente que el porcentaje de informalidad urbana se acerca al 50 ó 55\%, considerándose únicamente los procesos de acceso al suelo y a la vivienda, dejando por tanto a un lado otros procesos de informalidad urbana como la construcción irregular, los locales comerciales informales y otras prácticas. Las cifras identificadas en ciudades de otros países de la región -Venezuela, Colombia, Ecuador, Perú, El Salvador y, más recientemente, también Argentina y Uruguayindican igualmente que el proceso de producción informal del espacio urbano va en ascenso".

Un aspecto que menciona este autor, y que se ha modificado a través del tiempo es el hecho de que el crecimiento informal de la urbanización estaba más asociado a las grandes ciudades, y recientemente este proceso también se acentúa en las medianas y pequeñas ciudades Latinoamericanas.

Ante este aumento de los asentamientos informales, los gobiernos tratan de dar soluciones a la población a través de planes de regularización, sin embargo estos son aún muy insuficientes. Al mismo tiempo afirma que la mayoría de experiencias de regularización de asentamientos informales en América Latina inició su desarrollo a partir de la década del 80, generando una tradición investigadora creciente. Más recientemente, la discusión regional e internacional acerca de los programas de regularización alcanzó una relevancia aun mayor, convirtiéndose en objeto de la Campaña Global por la Seguridad en la Tenencia de la Vivienda, promocionada desde 1999 (Fernándes, 2008).

Por otra parte, el crecimiento de estos asentamientos informales en América Latina es más elevado que el crecimiento de la pobreza, es así que el tema exige una importante reflexión a la hora de pensar en las políticas públicas de los diferentes gobiernos. 
Finalmente, las consecuencias que trae consigo el crecimiento urbano informal, y menciona como una de las principales al aumento de la exclusión social y de la segregación espacial, así como la creciente y perversa asociación entre habitantes de asentamientos irregulares y criminales, dando lugar a una serie de políticas públicas represivas y reacciones negativas, colmadas de prejuicios de parte de la opinión pública.

Entre los problemas jurídicos con relación a la falta de seguridad individual de la tenencia de la tierra, hay que mencionar, además de la vulnerabilidad de los residentes frente a las acciones y políticas de desalojo forzado, también la falta de acceso amplio de los habitantes de asentamientos informales al crédito formal, así como, muy frecuentemente, la falta de reconocimiento de derechos básicos, como es disponer de una dirección.

De hecho, son millones los latinoamericanos que no disponen de una dirección oficial en la que recibir su correspondencia, lo que, entre otros factores, induce a la discriminación sistemática de estas personas a la hora de ingresar al mercado laboral. (Fernándes, 2008, p.3).

En síntesis los asentamientos informales traen aparejados inconvenientes a la población que vive en ellos, al plan de urbanización de cada ciudad, y provoca que la población circundante a esos asentamientos exprese su inconformidad con los mismos.

En el actual contexto de desequilibrios y brechas socioeconómicas cada vez más marcadas, en las áreas urbanas podemos hablar de una creciente segregación socio espacial, donde quienes tienen mayor poder adquisitivo son los que pueden acceder a mejores espacios residenciales y servicios, y en consecuencia a una mejor calidad de vida.

En este sentido, se hacen cada vez más patentes las diferencias sociales, provocando que la ciudad tenga la apariencia de un mosaico dividido en sectores bien definidos, barrios cerrados, villas miseria, barrios de clase media, etc.

De manera que el aglomerado San Miguel de Tucumán no escapa a esta escena, pues se ve claramente la expansión de las construcciones de barrios cerrados y countries en la zona de Yerba Buena, paralelo al crecimiento de los barrios de clase baja, como Villa Muñecas nuestra área de estudio, que presenta una visible informalidad y falta de planificación ya que se utilizan terrenos nos aptos para la construcción como las márgenes del Canal Norte y las vías del tren, y en muchos casos las familias recién formadas construyen sus casas en el mismo terreno de los padres por falta de recursos para comprar un terreno propio agravado por la escasa oferta inmobiliaria accesible para esta población de escasos recursos.

\section{PROCESO HISTÓRICO DE FORMACIÓN DE VILLA MUÑECAS EN EL CONTEXTO DEL AGLOMERADO DE SAN MIGUEL DE TUCUMÁN}

\section{Generalidades del crecimiento urbano de San Miguel de Tucumán}

Es importante tener en cuenta el crecimiento de la provincia en general y del Gran San Miguel de Tucumán en particular, para así posteriormente llegar a analizar el crecimiento del área 
bajo estudio. Con este fin se presentan a continuación algunos artículos referidos directamente a la temática del crecimiento urbano en nuestra ciudad, es conveniente aclarar que fueron resumidos a fin de extraer solo lo más relevante para esta investigación.

Para dar inicio a este apartado vamos a citar a M. Marranzino (1988) quien realiza una investigación acerca del crecimiento espacial de la ciudad de San Miguel de Tucumán, a partir de 1665 cuando la ciudad se instala en el sitio de la Toma, hasta 1980 de esta evolución histórica lo que nos interesa a los fines de este proyecto, es la formación y desarrollo del aglomerado actual del Gran San Miguel de Tucumán.

Dice el mismo autor que para 1955 "se observa un cambio en la forma del plano de San Miguel de Tucumán [...] a pesar de que las cuadras se conformaban en damero, lentamente la ciudad iba adoptando una forma estrellada, orientada con algunas vías de circulación notorias como la Avenida Benjamín Aráoz, Juan B. Justo, Mate de Luna, Sarmiento, calle Salta, etc."(Marranzino, 1988, p.39), se destacaban los ejes este-oeste representados por calles 24 de septiembre y Av. Mate de Luna y Aconquija; y eje sur-norte Calle Salta.

Asimismo continúa M. Marranzino, "debido a los intereses especulativos la ciudad fue creciendo ocupando así, superficies baratas o susceptibles de ser ocupadas sin ningún desembolso, lo que desencadenó el surgimiento de rancheríos carentes de la mayoría de los servicios públicos". Por otra parte "en estos años las Villas Yerba Buena y Marcos Paz dejaron de ser zonas residenciales de verano para ir siendo ocupadas gradualmente en forma permanente" (Marranzino, 1988, p. 41).

Y en lo que respecta a nuestra área de estudio, Marranzino observa en fotografías aéreas que en 1972 la ciudad de San Miguel de Tucumán se ha ido compactando mas dentro del casco urbano, lo que trajo aparejada la unión de Villa Santillán y Villa Muñecas y aparecían residentes a lo largo del camino que une la ciudad con el ex ingenio San José (Marranzino, 1988).

Ya en la década del '80, el proceso de expansión urbana del municipio de San Miguel de Tucumán produjo la conurbación con otros centros poblacionales para formar el Gran San Miguel de Tucumán, que abarca los departamentos de : SM de Tucumán, Cruz Alta ( Banda de Río Salí, Lastenia, Alderetes, El Corte y Los Gutiérrez), Yerba Buena( Marcos Paz, ex Ingenio San José), Tafí viejo (Villa Mariano Moreno, El Colmenar, Barrio diagonal Norte, Luz y Fuerza, Los Pocitos y Villa Nueva Italia)y departamento Lules y Manantial (Marranzino, 1988).

El crecimiento urbano de Tucumán y de su aglomerado principal, en particular estuvo ligada íntimamente a la actividad azucarera de la provincia; es mas en pleno auge de esta actividad (fines del S. XIX y principios del XX), el crecimiento poblacional fue altamente positivo, así pues se pone en evidencia que los altibajos económicos influyeron de forma directa en el proceso de urbanización y ocupación del espacio en el mismo San Miguel de Tucumán como en sus alrededores, de forma tal que en las épocas de crisis es cuando se forman las villas de emergencia y barrios pobres sin ningún ordenamiento ni servicios (Mansilla dice que en los $60 `$ es cuando aparece esta clase de urbanización), todo lo cual está en directa relación con la 
calidad de vida de los habitantes.

También en un estudio llevado a cabo por U. Müller en el periodo 1965 -1991 se analiza el crecimiento urbano del Gran San Miguel de Tucumán y se diferencian dos modalidades del proceso; así menciona que "durante el periodo 1965-1978 el área de la dinámica más alta de cambios de uso del suelo (representaba más del 50\% de la superficie total de la zona) formaba un círculo alrededor del centro urbano. A esta zona se agregaba otra de alta dinámica de cambio cuyo crecimiento se da en forma sectorial a lo largo de las avenidas Mate de Luna y Aconquija (hacia Yerba Buena) (Müller, 1993, p. 122). Sin embargo, continua diciendo este autor, esto cambia con el paso del tiempo y en 1991 las zonas circulares y sectoriales de crecimiento se vieron reemplazadas casi por completo por zonas puntuales, sobre todo en el área sur, a lo largo del Río Salí y en Alderetes y Villa Mariano Moreno, la mayoría zonas de vivienda de clases bajas y con predominancia de barrios ilegales y semilegales.

Continuando con lo referente al crecimiento urbano desordenado del aglomerado de San Miguel de Tucumán, vamos a seguir a M. Mansilla y F. Soria (2000), quienes plantean que "en esta última década (1990) se produjo una importante modificación del proceso tradicional de urbanización de SMT característico del periodo 1940-1980, estas modificaciones producidas en la década del ' 90 pueden resumirse, en una exagerada generalización, de la siguiente manera:

* Loteos por subdivisión de antiguos terrenos de gran extensión en áreas contiguas a la planta urbana, sin infraestructura básica, debido fundamentalmente a que las redes se limitaban a cubrir el área ya urbanizada y por otro lado, no existía un código, que regulara tales loteos.

* Adquisición individual, por compra o por invasión, de una fracción de terreno.

* Auto construcción de la vivienda.

* Lento proceso de incorporación a la red de servicios básicos.

* Incorporación a la estructura urbana por consolidación de los barrios: cuanto más lejos al centro, tanto más baja la clase social" (Mansilla y Soria, 2000, p. 106).

En todo este proceso, el papel del Estado en cuanto a regulación y planificación urbana es irrelevante, dando así paso al libre manejo del mercado inmobiliario a las grandes empresas privadas. En cuanto a esto Mansilla dice que en la década del ` 90 " aumentó la importancia del sector privado en la gestión urbana, por lo que el proceso de urbanización del GSM de Tucumán está en manos de empresas constructoras y no es el fruto de una adecuada planificación, sino el resultado de algunas negociaciones particulares; asimismo el Estado desempeña el rol de facilitador del acceso a la ampliación de las redes de servicios básicos, pero no es el responsable ante la comunidad sino ante las empresas" (Mansilla y Soria, 2000, p.121).

Otro trabajo que realiza aportes sobre el crecimiento urbano informal y la falta de planificación y participación del Estado es el de Natera Rivas (1998). Dicho autor señala que 
en la Argentina las Villa Miseria comienzan a establecerse a partir de la crisis del `29, sin embargo en Tucumán se tienen antecedentes recién en la década de 1950, y que esta aparición estuvo relacionada con la falta de una oferta habitacional a la que pudiera acceder población de bajos recursos (Natera Rivas, 1998, p. 12).

Como se mencionó anteriormente los lugares no aptos para la construcción (terrenos en la mayoría de los casos propiedad del gobierno) son los elegidos para la instalación de la Villa, estos lugares están representados por las márgenes de las vías del ferrocarril , o de canales de desagüe (como el Canal Norte y las vías del tren Belgrano en Villa Muñecas), áreas pantanosas o inundables como las márgenes del Río Salí, así como también terrenos en el interior mismo de la trama urbana que no tienen ninguna construcción, etc. En este sentido Natera Rivas indica que si bien en un principio las villas se asentaron en las periferias de la ciudad, con la expansión del aglomerado y la conurbación con otros centros las villas han quedado dentro de la ciudad (Natera Rivas, 1998).

Con respecto al crecimiento de los distritos jurisdiccionales del área metropolitana, del GSMT, S. Mansilla y F. Soria (2000) nos dicen que si bien la capital aumento su número de habitantes, disminuyo su participación relativa sobre el total de la población (de $41,4 \%$ en 1991 a $39.4 \%$ en 2001), lo que demuestra una marcada tendencia al crecimiento hacia la periferia, y esto es importante de analizar puesto que el área escogida para el presente trabajo se encuentra muy cercana a la periferia del GSMT.

En conclusión el aglomerado creció de forma espontánea, sin planificación hasta llegar a ser hoy un área metropolitana que sigue en crecimiento, sus periferias principalmente.

\section{Orígenes y consolidación del área}

Es esencial la revisión histórica de los diferentes momentos que se sucedieron desde el nacimiento de Villa Muñecas como zona de quintas periféricas de cítricos y hortalizas hasta llegar a ser hoy un barrio inserto en el entramado urbano de la ciudad. Dicha revisión se efectúa siempre dentro de un contexto general, es decir como parte del desarrollo del aglomerado de San Miguel de Tucumán.

A partir de 1821 la ciudad de San Miguel de Tucumán empieza a experimentar un cambio, por medio del cultivo y el procesamiento de la caña de azúcar, aunque si bien en un principio solo sirvió para impulsar la industria doméstica de los dulces y otras conservas (Marranzino, 1997). La industria del azúcar se inicio con un ingenio emplazado en la zona de El Bajo (por entonces un suburbio al este de la ciudad) y se incrementó y se expandió con 7 ingenios en la provincia hacia 1827.

Por esta época la ciudad mostraba una estructura y ordenación del espacio similar a las etapas anteriores, con sus plaza, iglesias y viviendas, pero con un incremento de la población en 16.822 habitantes, según el censo realizado en 1845, bajo la dirección del Dr. Gondra (Ricci, 1967). 
Para 1848 se instalaba el ingenio "San José", al noroeste de la ciudad (actual departamento Tafí Viejo), con lo que la mayoría de las fábricas de hallaban rodeando a San Miguel de Tucumán y formando pequeños núcleos poblacionales separados espacialmente pero ligados a la ciudad capital.

En la zona que se conoce actualmente como Villa Muñecas, (que por aquel entonces se extendía sobre los actuales barrios: Aguas Corrientes; Echeverría, y Viamonte), existían quintas dispersas de cítricos y el incipiente cultivo de la caña de azúcar impulsado por la instalación del ingenio antes mencionado. El poblamiento era escaso, tan solo algunas casas dispersas de los cuidadores de las quintas.

Para 1869 año del primer Censo Nacional de población y economía en la ciudad se relevaron un total de 37.559 habitantes.

Asimismo en el año 1870 se fijaban los nuevos límites de la ciudad determinados, a partir de la plaza principal en seis cuadras el norte, sur y oeste y cuatro hacia el este.

A partir de la llegada del ferrocarril, la ciudad adquirió un nuevo esquema de urbanización con la formación de nuevos núcleos: los llamados "poblados de estación" (Marranzino, 1997, p. 30), que irían creando asentamientos suburbanos. La instalación sucesiva, de las cinco estaciones de ferrocarril, desde 1876, hasta 1896, enmarcaron y cerraron a la ciudad con el denominado "cinturón de hierro" en dirección a los cuatro puntos cardinales.

Más específicamente fue la línea General Belgrano, (que tuvo varias denominaciones distintas a lo largo de su historia Ferrocarril Central Norte, Central Córdoba...) la que produjo la fundación de la estación Muñecas (en la intersección de las calles Viamonte y Av. Francisco de Aguirre), a fines del siglo XIX (1898, según las entrevistas a los informantes clave). Se puede establecer entonces que este es un importante momento en el cual se origina el poblamiento estable de este sector como tantos otros caseríos que nacieron y se consolidaron a lo largo de la provincia.

Con la llegada del ferrocarril, la población se incrementó considerablemente en un período corto de tiempo, y se componía básicamente de obreros ferroviarios, de la caña de azúcar y peones que trabajaban en la carga y descarga de productos o ganado desde los trenes. Según testimonios de un vecino: "frente a los corrales de hacienda, (que se extendían desde Viamonte a Ejercito del Norte al costado del ferrocarril) y hasta la calle Emilio Castelar, al sur se emplazaron rancheríos de los obreros que trabajaban con la hacienda. Era la llamada Villa "El Charqui" (porque cuando morían o se quebraban animales los carneaban y se los repartían entre los vecinos y hacían charqui)". Por lo tanto en torno a la estación se fue conformando un caserío con grupos de pobladores con diferentes ocupaciones que fueron armando sus ranchos muy precarios (de despunte de caña, casas de madera típicas de vagones que quedaban en desuso del tren, etc.) en diferentes sectores alrededor de la estación, provenían de Tucumán así como de las provincias limítrofes.

La provisión de servicios básicos en este periodo inicial de formación de Villa Muñecas era nula, puesto que según los testimonios no había ni siquiera caminos que comunicaran al barrio 
(visto como una isla en los planos de aquella época) con el centro de la ciudad; solo existían senderos transitables con dificultad y el medio de comunicación más utilizado por ese entonces era el ferrocarril, mientras que en general los demás servicios se instalaron posteriormente.

Por otra parte hay que tener en cuenta otros elementos de gran relevancia, que además del ferrocarril influyeron en la formación y crecimiento urbano de Villa Muñecas, fueron los Depósitos de Aguas Corrientes perteneciente Obras Sanitarias de la Nación (en la zona en que hoy se emplaza el barrio Aguas Corrientes), cuya construcción demandó una considerable cantidad de obreros. Según información de la SAT, el 15 de agosto de 1897, en una concurrida ceremonia, se colocó la piedra fundamental, inaugurándose así esta planta potabilizadora de agua en Villa Muñecas. El acto fue presidido por el entonces Gobernador de Tucumán, teniente coronel Lucas Córdoba, y el Intendente Municipal Zenón J. Santillán. Se cumplía así un viejo anhelo de la población de la ciudad de San Miguel de Tucumán, que hasta entonces se proveía de agua en aljibes y pozos domiciliarios, como en la época de la colonia, y si bien en un principio muchos vecinos no querían pagar la conexión, paulatinamente se fue instalando en toda la ciudad.

En esta época Villa Muñecas ya estaba consolidada como un barrio de la capital tucumana de clase media-baja, también íntimamente ligada a los talleres ferroviarios de Tafí Viejo, y al centro de la ciudad donde mucha gente se trasladaba diariamente a trabajar en el sector de la administración pública y en el servicio doméstico. El primer camino que comunica al barrio con el centro de la ciudad capital fue la calle Viamonte, era un precario sendero anegado en verano por las fuerte lluvias y con abundantes baches, por esta calle transitaban carretas "taxi" que por un monto determinado trasladaban a las personas hasta el barrio Jardín donde tomaban recién una línea de colectivo que los llevara hasta el centro, a trabajar o en busca de servicios básicos que no había en el barrio como escuelas, hospitales, etc. La primera línea de colectivos que llega hasta Villa Muñecas se instala en la década del '50 era la línea "H". Los servicios de energía eléctrica y agua potable, lentamente originan a extenderse, sin cubrir la totalidad del área.

Sin dudas al revisar la historia del área bajo estudio es imposible dejar de mencionar un lugar de relevancia y representativo de la vida social del barrio: la biblioteca Popular Miguel Lillo, fundada por un grupo de vecinos en febrero de 1929 por ese entonces se llamaba "Unión Ferroviaria", y en 1938 se le cambio el nombre a su denominación actual. En este establecimiento se realizaban bailes populares y reuniones sociales muy concurridas, no solo asistía gente del barrio sino también de los alrededores, y significaba un lugar simbólico que identificaba a Villa Muñecas. Hoy en día se siguen realizando actividades sociales, pero con menor concurrencia que en el pasado, la biblioteca se encuentra inserta en el programa CONABIP (Comisión Nacional de Bibliotecas Populares) desde donde se envía equipamiento ${ }^{2}$.

\footnotetext{
${ }^{1}$ Nótese la relevancia del ferrocarril.

${ }^{2}$ Proyectores, computadoras, libros, etc.
} 
Desde la década del '50 Villa Muñecas se va consolidando a través de loteos legales, por parte de algunos terratenientes de la actividad azucarera y de ferroviarios, provocando una la gran afluencia de empleados del ferrocarril y de empleados de las plantaciones de caña de azúcar quienes compraron estos lotes (de 10 por 70 metros en promedio) por un módico valor. Del mismo modo, según los testimonios quintas cítricas fueron vendidas en loteos legales urbanos por no poder seguir administrándolas, es el sector más antiguo de Villa Muñecas y el más favorecido en lo que respecta al aspecto socioeconómico. Es el caso de una finca cañera de grandes extensiones, cuyo propietario se apellidaba Barthaburu, se loteo para la construcción del Barrio Echeverría, de auto construcción, las viviendas mientras que los loteadores privados se encargaron de la construcción de los cordones cuneta, y de la plaza del barrio (información proporcionada por informante clave).

Otro elemento que impulsó la urbanización de la zona fue la escuela primaria Villa Muñecas Sud que nació a principio del siglo XX como un pequeño establecimiento en el pasaje $\mathrm{A}$. Willians y Viamonte. Luego entre Bulnes y Av. Francisco de Aguirre se funda la escuela Nacional José Manuel Lainez 240, que con posterioridad se traslada hacia su emplazamiento actual en Isabel la Católica y Federico Helguera; esta escuela fue creada en el marco del primer gobierno de Perón, quien impulso la creación de escuelas en todo el país.

\section{La proliferación de la informalidad urbana desde los años '60}

Ya en la segunda mitad del siglo XX se comienza a formar el área metropolitana del Gran San Miguel de Tucumán, que comprende un conjunto de ciudades y localidades, sin interrupción espacial (proceso de conurbación), formado por San Miguel de Tucumán (90 kilómetros cuadrados dentro del departamento Capital); Banda del Río Salí, Lastenia, Alderetes, El Corte, Los Gutiérrez (departamento Cruz Alta), Villa Mariano Moreno, Las Talitas, El Colmenar, Los Pocitos, Barrio Nueva Italia, Diagonal Norte, Luz y Fuerza, San José, Tafí Viejo (departamento Tafí Viejo), Marcos Paz, Yerba Buena, La Rinconada (departamento Yerba Buena), El Manantial (departamento Lules). La conurbación ya estaba consolidada a mediados de la década de 1960 y en este contexto Villa Muñecas adquirió otro protagonismo.

Como se sabe en 1966 se produce la mayor crisis que sufrió la provincia debido a la superproducción de azúcar, las consecuencias fueron devastadoras en todos los ámbitos; el cierre de 11 ingenios y la pérdida de gran cantidad de empleos directos e indirectos supusieron la llegada de población expulsada del campo a las zonas periféricas de San Miguel, lo que unido a la mayor diversificación económica de la ciudad que tendió a fijar en ella a su población, supuso que, lejos de disminuir, el número de habitantes aumentara, y se incrementara el ritmo de concentración de la población provincial en la capital, que en 1960 era del $35 \%$ y en 1970 pasó a ser del $48 \%$ del total provincial. Al tiempo que la población de Villa Muñecas era de aproximadamente 3200 habitantes $^{3}$. Hay que tomar en cuenta como dice

\footnotetext{
${ }^{3}$ Los datos son aproximados debido a que Villa Muñecas se encuentra en un mismo radio o fracción junto a otros barrios, es por eso que se dificulta la individualización del la población exacta del área. En este caso (censo de 1960), se localiza en la fracción 4, radio 8, circuitos 1 y 4 (San Miguel de Tucumán estaba subdividido en 8 circuitos).
} 
Mansilla (2008, p. 89) el crecimiento de la ciudad estuvo muy ligado a la industria azucarera, razón por la cual fue alto durante las crisis, de manera que la población migraba del campo a la ciudad en busca de trabajo.

En este período de crisis, el canal Norte (límite norte de la Capital tucumana) paso a representar un lugar propenso a la ocupación de población de clase baja conformándose un asentamiento informal. Según los testimonios, con la gran crisis de la cañera de 1966, se produce la llegada de los primeros pobladores a las márgenes del canal. Era gente que había quedado desempleada del campo y se vino la ciudad en buscar de un porvenir, pero por falta de recursos para una vivienda digna se instalaban en ranchos precarios.

Con el tiempo la urbanización se fue consolidando, hasta ser hoy un sector con visible desorganización en su trazado, persisten algunas casas de construcción precaria (de madera, chapa) aunque la mayoría son de material, cuentan con servicios básicos, y gran cantidad de viviendas se construyeron módulos habitacionales por parte del gobierno actual. A pesar de dichos avances urbanísticos, la condición de informalidad dominial persiste ante la fragilidad ecológica del emplazamiento del asentamiento.

En el Censo Nacional de Población de 1970, Villa Muñecas contaba con una población de aproximadamente 4100 habitantes ${ }^{4}$.

Asimismo no hay que dejar de recordar en este marco, un momento de la historia Argentina que marco a Villa Muñecas, la Dictadura Militar, pues en este barrio las fuerzas militares y de seguridad realizaron múltiples inhumaciones clandestinas entre 1975 y 1977, en un viejo pozo que proveía de agua al ferrocarril (los vecinos lo llaman "pozo de Vargas"). Dicho pozo estaba ubicado al costado de las vías, al interior de una finca en la que se cultivaba caña y luego citrus. En este sentido, "la producción de los enterramientos clandestinos como una práctica habitual a partir del desarrollo del Operativo Independencia le imprimió características específicas y distintivas a los procesos de disciplinamiento social que se desplegaron en esta zona y que tuvieron como principal operador el terror. Estos procesos involucraron al entramado social en su conjunto incluyendo tanto a los vecinos, sus interacciones, los sistemas de representaciones y la materialidad de la muerte" (Bertotti, 2006, p. 6).

Fue en este periodo cuando se produce un estancamiento en el crecimiento y desarrollo de Villa Muñecas, periodo del cual según los informantes logró salir gracias a la creación de los barrios lindantes como el FEPUT, bajo el impulso de los mismos produjo la llegada de nuevos servicios como la pavimentación ${ }^{5}$ y las cloacas.

Hay que recordar que en 1978 según testimonios de los vecinos fueron estafados por una supuesta empresa que les solicitó dinero para la obra de las cloacas, sin embargo esto no ocurrió y años más tarde (en 1983) recién empiezan a construirse primero en el barrio

\footnotetext{
${ }^{4}$ El área de estudio estaba comprendida en parte norte de la fracción 4 (radios 1, 2 y parte del 4), y fracción 5 (radio 1)

${ }^{5}$ Que hasta entonces eran los mismos vecinos quienes debían juntar fondos a través de rifas por ejemplo, para poder realizar la instalación de servicios como pavimento y cloacas en algunas cuadras.
} 
Echeverría y con posterioridad en Villa Muñecas; hasta entonces en las viviendas se utilizaban las fosas sépticas. En este mismo periodo se completó la provisión domiciliaria total de agua potable y energía eléctrica. Asimismo en esta época aparecen nuevos servicios: CAPs y la comisaría.

En la década de 1990, la ciudad de San miguel de Tucumán, debido al constante crecimiento de la población (según el censo nacional de 1991, 622.348 habitantes) y de superficies edificadas muestra características notables como asentamientos ilegales precarios, villas miseria, en los bordes septentrional (sector donde se emplaza Villa Muñecas) y meridional del aglomerado (Caillou 1995).

Durante el gobierno de Menem, cuando comienza a implementarse la reforma del Estado, los ferrocarriles fueron uno de los sectores más golpeados por los recortes presupuestarios y los procesos de privatización. De esta manera, el tren de pasajeros comienza a circular cada vez menos hasta que se cerró el servicio definitivamente, lo que derivó en el cierre de los talleres de Tafí Viejo, causando el despido de miles de trabajadores ferroviarios y Villa Muñecas es claramente afectada por este proceso. Fue en este periodo donde muchos pobladores se trasladaron en busca de trabajo a otros sectores de la provincia y a los alrededores de la ciudad capital.

En esta coyuntura es cuando se instalan algunas personas de bajos recursos en los terrenos liberados por el ferrocarril y se producen los asentamientos informales más recientes de Villa Muñecas (Villa Muñecas I, II y III).

Es recién en 1994 cuando se fundada primera escuela secundaria del barrio, en el mismo predio de la escuela primaria (aunque la ley prevé que solo puede haber una escuela por manzana) y gracias a la prestancia de los mismos vecinos se fueron recaudando fondo a través de rifas, loterías, donaciones etc., y se compraron casillas prefabricadas una cada año, hasta completar 5 aulas, donde se dictaban las clases, con la malaventura de que recién terminada un niño accidentalmente quemo la escuela, los vecinos esta vez acudieron al gobierno para que les diera una solución urgente (mientras tanto las clases se dictaban en la iglesia Santa Teresita), hasta que se construye finalmente el edificio de la escuela secundaria de comercio $\mathrm{N}^{\circ} 5$ "Ildefonso de las Muñecas", años en que Ramón Ortega era gobernador de la provincia (en 1994).

Hoy en día el barrio cuenta con provisión de agua potable, electricidad domiciliaria y alumbrado público, cloacas, pavimentación en las principales vías ${ }^{6}$ mientras las demás calles son de ripio, un CAPs (fundado en la década del `60), una comisaría, una iglesia católica y una evangelista, la biblioteca, una escuela primaria y una secundaria. Recorren el barrio 3 líneas de colectivos $(8,9$ y 19). Se destaca una fuerte diferenciación de la provisión de servicios entre los sectores más antiguos del barrio donde son más completos, y los asentamientos informales donde son deficientes, además de no poseer cloacas (actualmente utilizan fosas sépticas) ni gas natural. Al mismo tiempo hay que considerar el incremento poblacional del área para los censos de 1991 y 2001, que era de 5022 y 5778 habitantes respectivamente, mientras que la

\footnotetext{
${ }^{6}$ La Avenida Francisco de Aguirre acaba de ser pavimentada en 2011.
} 
proyección de población para el 2010 (utilizando la razón de crecimiento entre los dos censos antes mencionados), arroja la cifra de 6864 habitantes en el área ${ }^{7}$.

Por su particular historia, hoy en día se pueden observar en Villa Muñecas sectores que se diferencian por su fisonomía (tanto de las viviendas como el entramado). Al norte en las márgenes del canal y de las vías se pueden observar signos evidentes de pobreza y marginalidad, casas precarias con una estructura poco resistente de madera y chapas sumado a la falta de provisión de servicios, aunque en el sector intermedio, sobre la Av. Francisco de Aguirre (recientemente pavimentada), hay casas de material, con gran parte de los servicios. Hacia el sur de las vías hay un sector intermedio pero en mejores condiciones que los anteriores. Y finalmente al sur del barrio se encuentra el sector más favorecido, y el más antiguo a la vez, cuenta con todos los servicios y hay mayor cantidad de viviendas de clase media.

\section{CONSIDERACIONES FINALES}

Villa Muñecas es un barrio de clase baja, marcado por hitos de la historia de la provincia y del país, que fueron trazando la llegada de sus diferentes pobladores a lo largo de su proceso de crecimiento urbano. Desde siempre tuvo falencias en la provisión de los servicios lo cual provoca las quejas incesante de los vecinos hasta la actualidad en los sectores de asentamientos informales, por ejemplo, no hay servicio de cloacas ni gas natural; sin embargo el principal reclamo, como es común hoy en día, es una solución a la inseguridad.

Los orígenes del área se encuentran en diversos elementos, entre los principales están el establecimiento del ferrocarril que provoco el asentamiento estable de la población que se componía básicamente de obreros ferroviarios, de la caña de azúcar y peones que trabajaban en la carga y descarga de productos o ganado desde los trenes.

Otro de los elementos en los orígenes del área, son los Depósitos de Aguas Corrientes (1897) perteneciente Obras Sanitarias de la Nación, cuya construcción demandó una considerable cantidad de obreros que se instalaron definitivamente en el área.

Mientras que en la década del ' 50 se consolida la villa por medio de una urbanización legal y del fortalecimiento de los servicios (colectivos, comisaría, CAPs, etc.).

Desde la crisis del '66 y los años '70 se distingue una fase de estancamiento y proliferación de la informalidad urbana con elementos claves como el canal norte, pues es un lugar propenso a la ocupación de población marginal, de escasos recursos que no podía acceder a una vivienda y terreno propio por medios legales, en este periodo también se formaron los controvertidos asentamientos ilegales dispuestos al costado de las vías, son los denominados Villa Muñecas I, II y III (denominación que le dan los vecinos del lugar), el primer sector es el más antiguo se formo poco después de cerrada la estación de ferrocarril, en torno a la cual se

\footnotetext{
${ }^{7}$ Se realiza este cálculo a falta de los datos oficiales del INDEC por fracciones y radios censales, del último Censo Nacional realizado en 2010.
} 
asentaron algunas familias. El segundo sector se creó hace aproximadamente 15 años, cuenta con casas de material, alumbrado público, electricidad domiciliaria, agua potable, el recolector de residuos pasa una, y el sector III hace 30 años. Asimismo se destaca en la década del '70, un elemento de estigmatización como fue el pozo de Vargas símbolo de la dictadura militar, que produjo una pérdida de atractivo del barrio.

Ya en la década de los '80 de progreso relativo motivado por la cercanía de nuevos barrios planificados como el FEPUT, y la instalación de cloacas, gas, y pavimentación de la calle Viamonte y calles principales.

Desde los '90 a la actualidad en que se recrudece la informalidad ante el cierre del ferrocarril, cerrados durante el gobierno de Menem provocando la fuerte decadencia del área, y haciendo que se incrementaran los asentamientos informales en los terrenos fiscales liberados por el ferrocarril.

Finalmente hoy en día se puede caracterizar a Villa Muñecas como un área urbana con marcada desigualdad tanto social, de infraestructura y de servicios urbanos, entre los diferentes sectores que componen este barrio. Esta diferenciación también es patente en la percepción de la población según el sector al que pertenezcan, es así que la mayor parte de la población correspondiente al sector más antiguo opina que los asentamientos son focos de delincuencia y que la inseguridad esta cada vez más presente, mientras que la población de dichos asentamientos no piensan del mismo modo.

\section{BIBLIOGRAFÍA}

BERTOTTI, C. La producción de la muerte y las transformaciones del mundo de la vida en el barrio de Villa Muñecas. Tucumán: Instituto Gino Germani, Facultad de Ciencias Naturales e Instituto Miguel Lillo, Universidad Nacional de Tucumán, 2006.

CAILlOU, M. y CUSA, A. El Gran San Miguel de Tucumán: un caso de metropolización en la Argentina en las dos últimas décadas. Revista Geográfica, 1997, nº 123, p. 63-76.

CAILlOU, M. Evolución de la población del Gran San Miguel de Tucumán según los censos nacionales 1960-1970-1991. Breves Contribuciones del Instituto de Estudios Geográficos, $1995, \mathrm{n}^{\circ} 9$, p. 7-37.

CAILlOU, M. Serie ciudades intermedias: San Miguel de Tucumán. Geoespacios, 1997, n 11, p. 3-12.

FERNÁNDES, E. Consideraciones generales sobre las políticas públicas de regulación de asentamientos informales en América Latina. Revista EURE, 2008, n¹02, p. 25-38.

MANSILLA, S. y SORIA, F. Expansión Territorial del Gran San Miguel de Tucumán desde 1990. Breves contribuciones del IEG, 2000, nº 12, p. 105-124. 
MANZANAL, M. El primer ferrocarril a Tucumán. Revista Población y Sociedad, 2000, $\mathrm{n}^{\circ}$ 8/9, p. 1-45.

MARRANZINO, M. San Miguel de Tucumán: efectos de su expansión en el espacio horizontal. Breves contribuciones del IEG, Monografía I, 1988.

MARRANZINO, M. Evolución geohistórica del Gran San Miguel de Tucumán. Revista Geoespacios, 1997, n 11, p. 23-38.

MONAYAR, V. Informalidad urbana y acceso al suelo, Acciones y efectos de la política habitacional en la ciudad de Córdoba-Argentina. Revista Digital Territorios, 2011, no 24, p. 113-130.

MÜLLER, U. El crecimiento urbano del Gran San Miguel de Tucumán entre 1965 y 1991. Revista Población y Sociedad, 1993, nº 8-9, p. 115-152.

NATERA RIVAS, J. Urbanización de la pobreza: procesos migratorios y formación de periferias de invasión en una ciudad intermedia Argentina. Universidad de Málaga. Hemeroteca IEG, 1998.

RICCI, T. Evolución de la ciudad de Tucumán: Contribución a su estudio. Tucumán: Universidad Nacional de Tucumán, 1967.

\section{RECURSOS ELECTRÓNICOS}

SMOLKA, M. O. 2003. Informalidad, pobreza urbana y precios de la tierra. Land Lines Article [En línea]. Enero 2003. <http://www.lincolninst.edu/pubs/825_Informalidad--pobrezaurbana-y-precios-de-la-tierra>. [12 de noviembre de 2011].

Aguas del Tucumán. Historia de la provisión de agua potable a la ciudad de San Miguel de Tucumán [En línea].

2001.<http://www.aguasdeltucuman.com.ar/admincont.php?paginaDo=./contenidos/1historia. $\underline{\text { htm }}>$. [16 de octubre de 2011].

(C) Copyright Romina Natalí Centeno, 2013.

(C) Copyright GeoGraphos, 2013.

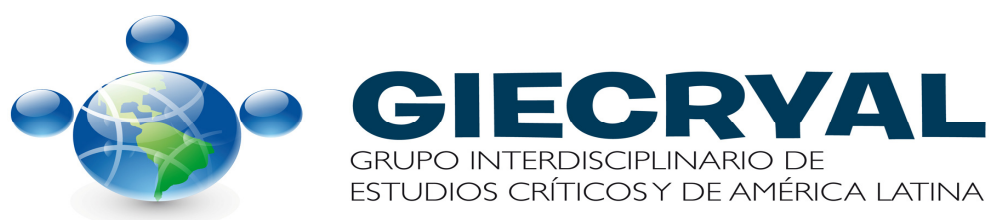

